\title{
TÉCNICAS DEAISLAMIENTO Y PURIFICACIÓN DE OOQUISTES DE Sarcocystis aucheniae APARTIR DE INTESTINO DELGADO DE PERROS EXPERIMENTALMENTE INFECTADOS
}

\author{
TechniQues for the Isolation and Purification of Sarcocystis aUCheniae \\ OOCYSTS FROM SMALL INTESTINE OF EXPERIMENTALLY INFECTED DOGS
}

\author{
Fiorella Zacarías S. ${ }^{1}$, Rosa Sam T. ${ }^{1,4}$, Daphne Ramos D. ${ }^{2}$, Orlando Lucas A. ${ }^{3}$, \\ Juan Lucas L. ${ }^{2}$
}

\section{Resumen}

\begin{abstract}
Se evalúan procedimientos para la rápida y eficiente purificación de ooquistes y eporoquistes de Sarcocystis aucheniae (Sa), a partir del intestino delgado de perros experimentalmente infectados vía oral con 400 macroquistes de Sa provenientes de carne de alpacas naturalmente infectadas. Se recolectó la mucosa del intestino delgado. Las muestras fueron lavadas por centrifugación con buffer salino fosfato y homogenizadas y centrifugadas. Se obtuvo grandes cantidades de ooquistes adheridos a las microvellosidades intestinales. En el primer procedimiento, los ooquistes recibieron un tratamiento enzimático con tripsina al 5\% resultando 50\% de separación. En el segundo fueron tratados con una solución de hipoclorito de sodio al $2.6 \%$ lográndose una separación parcial $(80 \%)$. En el tercero fueron centrifugados con una gradiente de densidad discontinua de bromuro de potasio obteniéndose una separación de $99 \%$. Este último procedimiento permitió la obtención de ooquistes de Sa en cantidades relevantes, purificados y sin pérdida de la viabilidad.
\end{abstract}

Palabras clave: ooquistes, Sarcocystis, bromuro de potasio, purificación

\section{Abstract}

Procedures were evaluated for the rapid and efficient purification of oocysts and esporocysts of Sarcocystis aucheniae (Sa) from the small intestine of experimentally infected dogs with 400 Sa macrocysts obtained from meat of naturally infected alpacas. The mucosa of the small intestine was removed. Samples were washed by centrifugation with PBS, homogenized and centrifuged. Large quantities of oocysts attached to the

\footnotetext{
${ }^{1}$ Laboratorio de Microbiología y Parasitología Veterinaria, ${ }^{2}$ Laboratorio de Salud Pública y Salud Ambiental, ${ }^{3}$ Laboratorio de Bioquímica, Nutrición y Alimentación Animal, Facultad de Medicina Veterinaria, Universidad Nacional Mayor de San Marcos, Lima

${ }^{4}$ E-mail: kueylan@hotmail.com
}

Recibido: 9 de abril de 2012

Aceptado para publicación: 17 de febrero de 2013 
intestinal microvilli were obtained. In the first procedure, an ezimatic treatment with 5\% tripsin was used resulting in 50\% oocyst separation. In the second procedure samples were treated with $2.6 \%$ sodium hypoclorite solution achieving $80 \%$ separation. In the third procedure, samples were centrifuged with a discontinuous density gradient of potassium bromide rendering $99 \%$ oocyst separation. The later procedure allowed obtaining relevant quantities of purified Sa oocysts and without loss of viability.

Key words: oocysts, Sarcocystis, potassium bromide, purification

\section{INTRODUCCIÓN}

La sarcocistiosis, también denominada sarcosporidiosis, es una enfermedad parasitaria producida por un protozoo del género Sarcocystis, Clase Sporozoea y Phylum Apicomplexa, en el cual se han clasificado hasta 130 especies (Fayer, 2004). Se tiene dos especies que afectan a la alpaca: $S$. aucheniae (Sa) y S. lamacanis, formando macroquistes en músculo esquelético y cardiaco, respectivamente (Leguía, 1991), y una especie que afecta al guanaco: $S$. tilopoidi (Gorman et al., 1984; Beldomenico, 2003).

La prevalencia de estas parasitosis en camélidos sudamericanos (CSA) puede ser muy elevada, habiendo reportes de hasta $100 \%$ en animales mayores de 2 años de edad (Castro, 1974; Mostajo, 1983). Este protozoo posee un ciclo de transmisión indirecto digenético que requiere para su desarrollo de un hospedero definitivo carnívoro (canidos), en los que ocurre la fase sexual del ciclo. Los herbívoros (alpaca, llama, guanaco) son los hospedadores intermediarios donde se desarrolla la fase asexual del parásito (Fayer, 2004). Los CSA se infectan por el consumo de ooquistes que dan origen a esquizontes en el endotelio vascular y a bradizoitos en quistes visibles en la musculatura esquelética y cardíaca (Leguía, 1991).

La sarcocistiosis repercute negativamente en la eficiencia productiva y ganancia de peso de los CSA (Chávez et al., 2008) al ocasionar dificultad motora, la cual está asociada a la acción de la sarcocistina, toxina hemolítica y hemoaglutinante, que libera el parásito y cuyo blanco es el sistema nervioso central (Azumendi, 1995), así como cuadros febriles e inclusive la muerte (Gorman et al., 1984). Además, causa grandes mermas en el valor comercial de las canales por decomisos en el camal y rechazo de la carne en los mercados (Concha, 1999).

El consumo de carne con quistes genera en el hombre una zoonosis tóxica con signos gastroentéricos. Además, hay dos especies de Sarcocystis (S. hominis y $S$. suihominis) que tienen como hospedero definitivo al hombre (Piekarski et al., 1978; Fayer et al., 1979; Moreno, 2003; Fayer, 2004), quien se infecta por consumo de carne parasitada cruda o poco cocida de cerdo y bovino. Esta zoonosis causa diversas complicaciones en la salud del hombre, y su alta prevalencia se asocia a estratos socioeconómicos bajos y condiciones sanitarias pobres (Wilairatana et al., 1996; Clavel et al., 2001; Nichpanit et al., 2010), como los encontrados en las zonas altoandinas del Perú (Leguía y Casas, 1999).

En este contexto se requiere de estudios adicionales para la búsqueda de métodos y herramientas de control que permitan disminuir las pérdidas de productividad animal, así como interrumpir el ciclo biológico del parásito. El presente trabajo tuvo como objetivo desarrollar un procedimiento rápido y eficaz para la depuración de ooquistes de Sa de la mucosa intestinal de perros experimentalmente infectados. 


\section{Materiales y Métodos}

\section{Animales}

El estudio se realizó en las instalaciones del Laboratorio de Inmunología de la Facultad de Medicina Veterinaria (FMV), Universidad Nacional Mayor de San Marcos (UNMSM), Lima. Se utilizaron cinco perros cruzados machos y hembras, vacunados y desparasitados, de aproximadamente tres meses de edad. A los canes se les realizó un análisis coproparasitológico previo para descartar posibles infecciones parasitarias.

\section{Infección Experimental}

Los cachorros fueron infectados vía oral con 400 macroquistes de Sarcocystis aucheniae obtenidos de músculos del cuello de alpacas infectadas naturalmente y que fueron beneficiadas en el camal de la ciudad de Huancavelica, Perú. El día 12 post infección se determinó la eliminación de ooquistes en las heces de los cachorros infectados mediante exámenes coproparasitológicos por el método de flotación con solución salina saturada. Los cachorros que eliminaron ooquistes fueron sacrificados siguiendo las recomendaciones del Comité de Ética y Bienestar Animal de la FMV- UNMSM.

\section{Depuración de los Ooquistes}

Se extrajo el intestino delgado, desde el píloro hasta la porción final del íleon, y se eliminó el contenido intestinal mediante lavados con agua destilada. La mucosa fue recolectada mediante raspado profundo con ayuda de una lámina porta objeto, obteniéndose una muestra equivalente a $7 \mathrm{ml}$ por animal. Las muestras fueros lavadas por centrifugación (3000 $\mathrm{g}$ por $10 \mathrm{~min}$ a $4{ }^{\circ} \mathrm{C}$ ) con buffer salino fosfato (PBS) $0.15 \mathrm{M}, \mathrm{pH}$ 7.2, estéril, y el sedimento fue almacenado en solución de PBS más antibiótico (100 U $\mathrm{ml}^{-1}$ de penicilina, $100 \mu \mathrm{g} \mathrm{ml}^{-1}$ de estreptomicina y $1.25 \mu \mathrm{g} \mathrm{ml}^{-1} \mathrm{de}$ fungizone). Estas muestras fueron sometidas a un homogenizador eléctrico a alta velocidad en tres oportunidades (dos min cada vez) con intervalos de $20 \mathrm{~s}$. El producto se centrifugó a $250 \mathrm{~g}$ por $10 \mathrm{~min}$.

El sedimento obtenido por la centrifugación fue sometido a procedimiento químico, que se desarrolló en tres fases. En la primera se agregó tripsina (tratamiento enzimático) al 5\% (Murphy y Manfield, 1999), manteniéndose en constante agitación por $2 \mathrm{~h} 30 \mathrm{~min}$ a $37^{\circ} \mathrm{C}$. Luego se lavó por centrifugación con PBS y se determinó el porcentaje de liberación de ooquistes.

En una segunda fase, el sedimento fue tratado con hipoclorito de sodio (NaOCL) al 2.6\% (Cawthorn et al., 1986) en proporción de $2 \%$ de mucosa y $15 \%$ de NaOCL, mezclándose en agitación constante a temperatura ambiente por $1 \mathrm{~h} 30 \mathrm{~min}$. Luego se procedió a determinar el porcentaje de liberación de ooquistes de la forma antes descrita.

La purificación final de la muestra correspondió a la tercera fase, y se realizó con la técnica de centrifugación con bromuro de potasio (KBr) (Elsheikha et al., 2003, 2006), en una gradiente de densidad discontinua en tres concentraciones: 5, 15 y $25 \%$ (w/v). En un tubo falcón con $4 \mathrm{ml}$ de muestra de ooquistes, se agregó $7 \mathrm{ml}$ de $\mathrm{KBr}$ al 5\%, $7 \mathrm{ml}$ de $\mathrm{KBr}$ al $15 \%$ y $8 \mathrm{ml}$ de $\mathrm{KBr}$ al $25 \%$. Se centrifugó a $16000 \mathrm{~g}$ por $1 \mathrm{~h}$ a $4{ }^{\circ} \mathrm{C}$ y se extrajo el halo blanco formado entre las concentraciones de 5 y $15 \%$ de $\mathrm{KBr}$, el cual fue lavado dos veces con PBS. Se determinó el porcentaje de ooquistes liberados.

En las tres técnicas empleadas para la purificación de los ooquistes de $S$. aucheniae (tripsina, NaOCL, KBr) se empleó la muestra de mucosa obtenida mediante el raspado del intestino delgado. La liberación de células intestinales de los ooquistes se determinó con ayuda de un hemocitómetro. Se observó la solución al microscopio y el porcentaje de liberación de ooquistes se determinó en base al número de ooquistes liberados dividido entre el total de ooquistes. 


\section{Resultados}

Los ooquistes adheridos a las microvellosidades intestinales se muestran en la Fig. 1. La adhesión de los ooquistes fue extremadamente compacta, por lo que previamente se ensayaron diversas concentraciones, tiempos y temperaturas de incubación con tripsina, determinándose la concentración del $5 \%$ por $2 \mathrm{~h} 30$ min a $37^{\circ} \mathrm{C}$ como las condiciones apropiadas. Con la técnica de aislamiento enzimático usando tripsina al $5 \%$ se obtuvo el $50 \%$ del desprendimiento de los ooquistes de las microvellosidades (Fig. 2).

Con el tratamiento con hipoclorito de sodio al $2.6 \%$ se mejoró el aislamiento en un
$80 \%$ pues se logró desintegrar restos de residuos orgánicos de las microvellosidades intestinales. De esta forma los ooquistes se hallaron intactos y libres pero aún se hallaron restos celulares (Fig. 3). Con la técnica de purificación con centrifugación con solución de gradiente de densidad discontinua de $\mathrm{KBr}$ se logró un $99 \%$ de ooquistes libres de partículas extrañas (Fig. 4). Estos ooquistes se encontraron congregados en un halo blanquecino observado en la interfase entre las soluciones de $\mathrm{KBr}$ al 5 y $15 \%$ (Fig. 5). Se aislaron $10 \times 10^{6}$ ooquistes, los cuales medían $18.8 \mathrm{x}$ $15.4 \mu \mathrm{m}$, con esporoquistes de $15.4 \times 1.9 \mu \mathrm{m}$. Los ooquistes se recuperaron intactos pues se observaron los dos esporoquistes unidos por la membrana del ooquiste (Fig. 6).

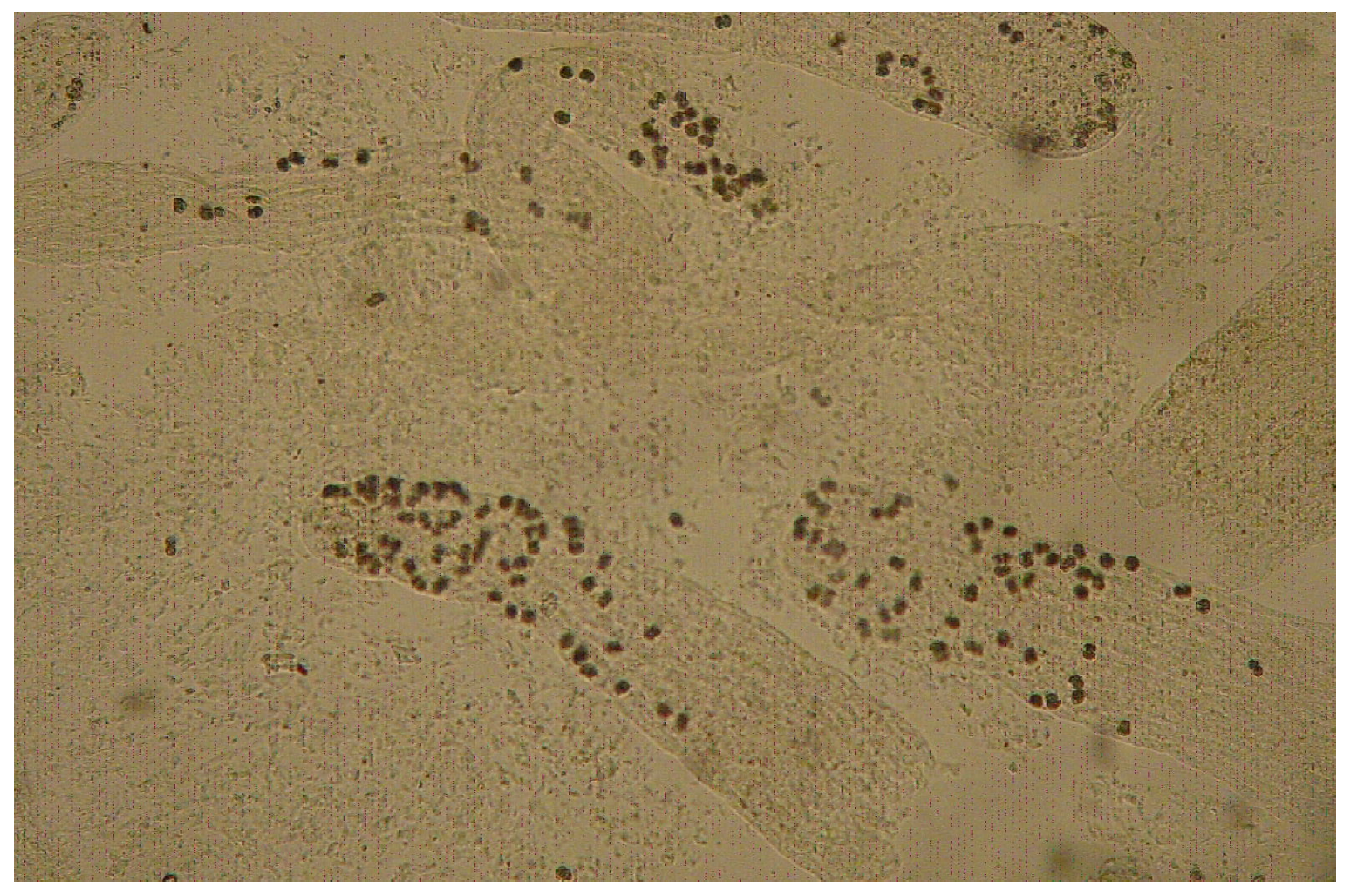

Figura 1. Ooquistes de Sarcocystis aucheniae adheridos a las microvellocidades de las células del intestino delgado de perros experimentalmente infectados (100X) 


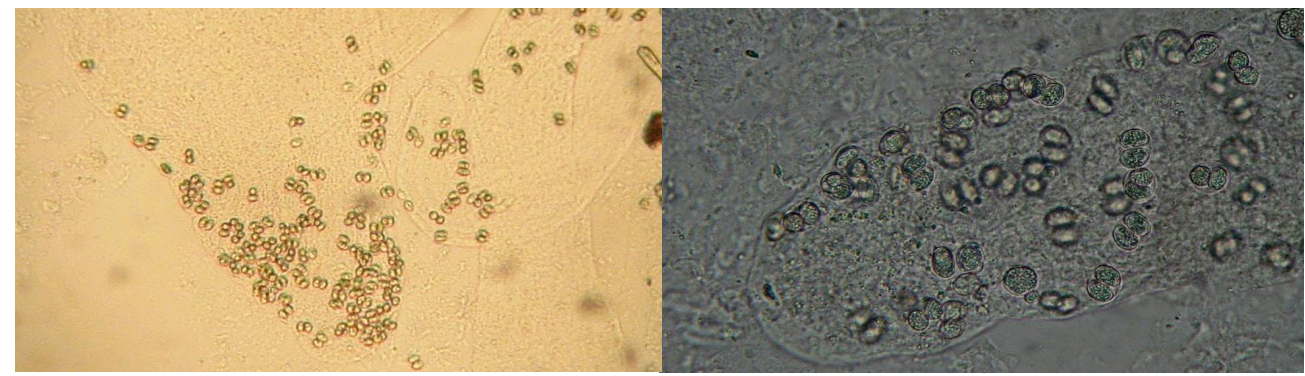

Figura 2. Desprendimiento parcial de los ooquistes de Sarcocystis aucheniae de las microvellosidades intestinales usando tripsina al 5\%. Izquierda: 100X; derecha: 400X

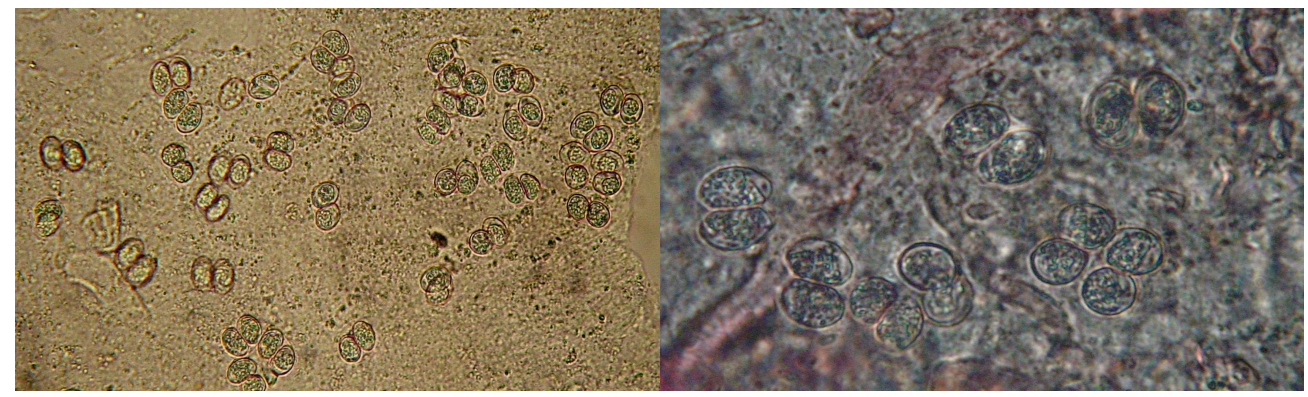

Figura 3. Desprendimiento de ooquistes de Sarcocystis aucheniae de las microvellosidades intestinales usando hipoclorito de sodio al 2.6\% ( $\mathrm{NaOCl})$. Izquierda: 100X; derecha: $400 \mathrm{X}$

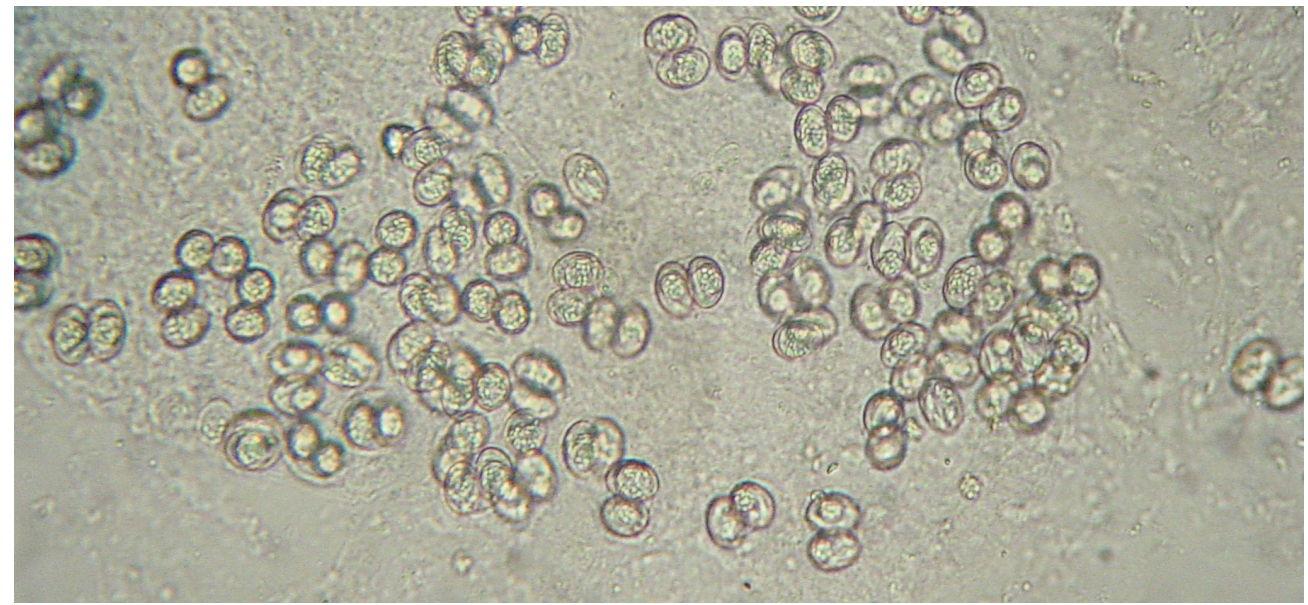

Figura 4. Purificación de ooquistes de Sarcocystis aucheniae mediante la técnica del bromuro de potasio $(\mathrm{KBr})$, en una gradiente de densidad discontinua en tres concentraciones: 5 , 15 y $25 \%(w / v)(400 X)$ 


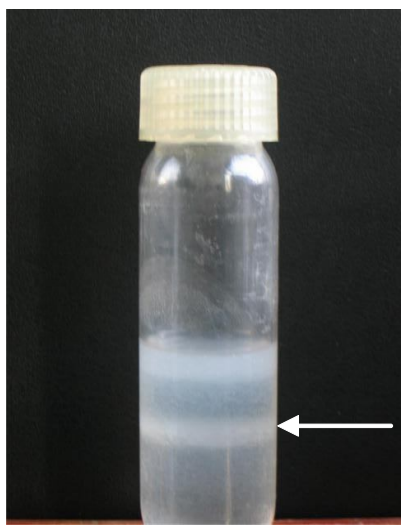

Figura 5. La purificación final de ooquistes de Sarcocystis aucheniae obtenida mediante centrifugación con la gradiente de densidad discontinua de bromuro de potasio $(\mathrm{KBr})$ se observa en el halo blanquecino (flecha blanca) entre las concentraciones de $\mathrm{KBr}$ de 5 y $15 \%$

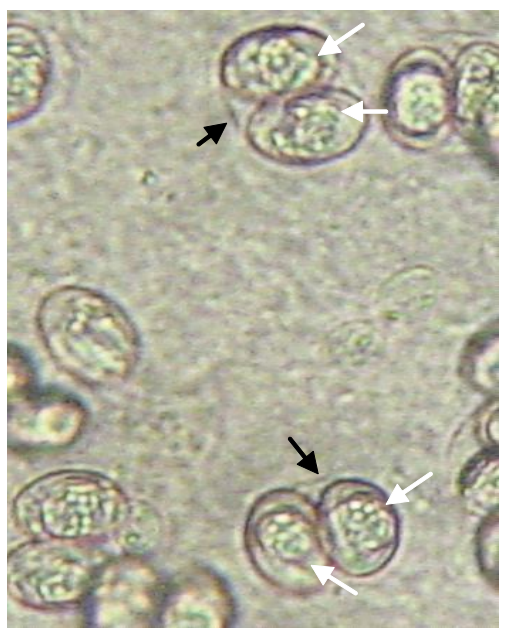

Figura 6. Ooquistes de Sarcocystis aucheniae recuperados intactos. Se puede observar dos esporoquistes (flechas blancas) unidos por la membrana del ooquiste (Flechas negras) (400X)

\section{Discusión}

El intestino delgado de los perros infectados con Sa contiene poblaciones de ooquistes y esporoquistes del parásito en sus diferentes estadios, los cuales podrían utilizarse para obtener grandes cantidades de ooquistes purificados. Sin embargo, el care- cer de un método práctico y confiable para separar las células parasitadas de las no parasitadas de la pared intestinal se dificulta la obtención de material purificado.

El presente trabajo establece un protocolo con el cual superar esta limitante. El uso de la técnica de centrifugación con $\mathrm{KBr}$ en una gradiente de densidad discontinua ya ha- 
bía sido ensayado con otras especies de Sarcocistys. Elsheikha et al. (2003) describieron un procedimiento similar al realizado en el presente estudio, consiguiendo purificar esporoquistes en grandes cantidades y viables de $S$. neurona de zarigüeyas (Virginiana didelfo). La purificación mediante una gradiente de densidad discontinua de BrK en tres concentraciones $(5,15$ y $25 \%)$ aprovecha la diferencia de densidad de los diferentes componentes celulares y morfología de los ooquistes. Los elementos más pequeños conseguirán atravesar más rápidamente las diferentes capas de los gradientes hasta situarse en el fondo, mientras que los de mayor tamaño y peso quedan en capas superiores del gradiente.

El desprendimiento de los ooquistes de las microvellosidades del intestino delgado de los perros experimentalmente infectados se consiguió con el uso de tripsina al $5 \%$ por $2 \mathrm{~h} 30$ min a $37^{\circ} \mathrm{C}$. Murphy y Mansfield (1999) obtuvieron un aislamiento inicial de ooquistes de $S$. neurona a partir de zarigueyas utilizando tripsina al $2 \%$ en PBS y $5 \%$ de taurocolato de sodio e incubadas a $37{ }^{\circ} \mathrm{C}$ con $5 \%$ de $\mathrm{CO}_{2}$. Estas condiciones ya habían sido descritas en aislamientos de ooquistes de $S$. capracanis, S. cruzy y S. Tenella (Cawthorn et al., 1986).

En el presente estudio, gran parte de los ooquistes continuaron adheridos a las microvellocidades de las células del intestino delgado pese al uso de la tripsina al $5 \%$, por lo que se utilizó hipoclorito de sodio al $2.6 \%$ incubado a temperatura ambiente por $90 \mathrm{~min}$, similar al procedimiento realizado por Cawthorn et al. (1986). Esto facilitó la separación de ooquistes y esporoquistes de las células intestinales y restos fecales, consiguiéndose así un importante desprendimiento y aislamiento parcial de los ooquistes de $\mathrm{Sa}$, pero no se eliminó el total de vestigios celulares. El uso de la técnica de centrifugación con $\mathrm{KBr}$ en una gradiente de densidad discontinua consiguió purificar el $99 \%$ de los ooquistes de $\mathrm{Sa}$, tasa alta de recuperación y en fracciones mucho más limpias, lo que concuerda con lo observado por Elsheikha et al. (2003), y que posteriormente se confirmaría cuando se usó como técnica para obtención de ooquistes y esporoquistes de $S$. neurona para evaluar su diversidad genética (Elsheikha et al., 2006).

Este método de purificación proporciona la base para futuros experimentos a desarrollarse, como el aislamiento de ooquistes individuales o esporoquistes, así como la posterior desenquistación de los mismos. La liberación de los esporozoitos serviría para estudios antigénicos que determinarían los epítopos promotores de anticuerpos.

\section{Conclusiones}

La técnica de centrifugación mediante una gradiente de densidad discontinua de bromuro de potasio permite la obtención de ooquistes de Sarcocystis aucheniae con un 99\% de pureza, a partir de mucosa intestinal de perros experimentalmente infectados.

\section{Literatura Citada}

1. Azumendi JI, Grana I, Rey YA, Pinzonc C, Forero LF, Pérez LF. 1995. Efectos de la toxina de Sarcocystis (sarcocistina). Rev Salud Animal 17: 273-284.

2. Beldomenico PM, Uhart M, Bono MF, Marull C, Baldi R, Peralta JL. 2003. Internal parasites of free-ranging guanacos from Patagonia. Vet Parasitol 118: 71-77.

3. Castro J. 1974. Sarcocystis auchenia en llamas (Lama glama). Rev Inv Pec, IVITA 3: 91-92.

4. Cawthorn R, Reduker D, Speer C, Dubey J. 1986. In vitro excystation of Sarcocystis capracanis, Sarcocystis cruzi and Sarcocystis tenella (Apicomplexa). J Parasitol 72: 880-884. 
5. Chávez A, Leyva V, Panez S, Ticona D, García W, Pezo D. 2008. Sarcocistosis y la eficiencia productiva de la alpaca. Rev Inv Vet Perú 19: 160-167.

6. Clavel A, Doiz O, Varea M, Morales S, Castillo FJ, Rubio MC, Gomez-Lus $\boldsymbol{R}$. 2001. Molestias abdominales y heces blandas en consumidor habitual de carne de vacuno poco cocinada. Enferm Infec Microbiol Clin 19(1): 29-30.

7. Concha S. 1999. Strategical plan of communication in marketing for the open consumption of alpaca's meat in Arequipa-Peru. In: Gerken M, Renieri C (eds). Progress in South American Camelids Research. Wageningen: The European Association for Animal Production. p 122-131.

8. Elsheikha H, Schott H, Mansfield L. 2006. Genetic variation among isolates of Sarcocystis neurona, the agent of protozoal myeloencephalitis, as revealed by amplified fragment length polymorphism markers. Infect Immun 74: 34483454.

9. Elsheikha H, Murphy A, Fitzgerald S, Mansfield L, Massey J, Saeed M. 2003. Purification of Sarcocystis neurona sporocysts from opossum (Didelphis virginiana) using potassium bromide discontinuous density gradient centrifugation. Parasitol Res 90: 104-109.

10. Fayer R. 2004. Sarcocystis in animal and human infections. Clin Microbiol Rev 17: 894-902.

11. Fayer R, Heydorn AO, Johnson AJ, Leek RG. 1979. Transmission of Sarcocystis suihominis from humans to swine to nonhuman primates (Pan troglodytes, Macaca mulatta, Macaca irus). Z Parasitenkd 59: 15-20.
12. Gorman TR, Alcaíno HA, Muñoz H, Cunazza C.1984. Sarcocystis sp. in guanaco (Lama guanicoe) and effect of temperature on its viability. Vet Parasitol 15:95-101.

13. Leguía. 1991. The epidemiology and economic impact of llama parasites. Parasitol Today 7: 54-56.

14. Leguía G Casas E. 1999. Enfermedades parasitarias y atlas parasitológico de camélidos sudamericanos. Lima: Ed De Mar. $190 \mathrm{p}$.

15. Moreno M. 2003. Higiene e inspección de carnes. 2. Madrid: Diaz de Santos. $593 \mathrm{p}$.

16. Mostajo W. 1983. Sarcocistiosis en alpacas beneficiadas en el camal municipal de Santa Rosa. Tesis de Médico Veterinario y Zootecnista. Puno: Univ Nacional del Altiplano. $68 \mathrm{p}$.

17. Murphy AJ, Mansfield LS.1999. Simplified technique for isolation, excystation, and culture of Sarcocystis species from opossums. J Parasitol 85: 979-981.

18. Nichpanit S, Nak W, Wongsaroj T, Nithikathkul C. 2010. First large scale of human Sarcocystis hominis in Thailand. TRCT 2(1): 1-5

19. Piekarski G, Heydorn AO, Aryeetey ME, Hartlapp JH, Kimmig P. 1978. Clinical, parasitoligical and serological investigations in sarcosporidosis (Sarcocystis suihominis) of man. Immun Infekt 6(4): 153-159.

20. Wilairatana $P$, Radomyos $P$, Radomyos B, Phraevanich R, Plooksawasdi W, Chanthavanich $P$, et al. 1996. Intestinal sarcocystosis in the Thai laborers. Southe Asian J Trop Med Public Health 27: 43-46. 